\title{
Using Cellular Automata for Grid-Based Fishery Management
}

\author{
Sing-Chou Fong \\ Professor, College of Marine Sciences, National Sun Yat-sen University, Kaohsiung, Taiwan \\ Email: scfong35@gmail.com
}

How to cite this paper: Fong, S.-C. (2019) Using Cellular Automata for Grid-Based Fishery Management. Agricultural Sciences, 10, 249-258.

https://doi.org/10.4236/as.2019.103021

Received: January 14, 2019

Accepted: March 8, 2019

Published: March 11, 2019

\begin{abstract}
This report introduced new concept and technics for a grid-based fishery management system. The fishing ground was first divided into small grid of equal area, each with predefined longitudes and latitudes (both 0.033 degrees or approximately $2 \times 2$ nautical miles in this study). All grids were laid and formatted into a Microsoft-Excel spreadsheet system, as defined by the coastline. Individual sheets were also constructed to represent different ecological characters, serving as supporting data of the main grid-map. Including individual fishing record, water depth, wind \& current vector, benthic character, etc. Cellular automata (CA) mathematics was applied for simulation studies. They were programmed on the built-in Visual BASIC langrage in EXCEL. In a three-year research project, the author was able to accomplish the following major results: 1) An EXCEL-based spreadsheet system for storage of fishing effort in each grid. Provided that data of fishing yield is also available for each grid, research model for fishery management can be constructed, leading toward solutions for total allowable catch (TAC) as well as maximum economic yield (MEY). 2) A multi-layered, 2-dimentional spreadsheet system demonstrating the distribution of relative intensity for individual grids. The system can be decked up with different ecological data for more advanced studies. 3) Estimation of the nearest distance between two special grids as well as fishing harbors. This would help in more efficient navigation management and allocation of fishing rights for the fishing vessels.
\end{abstract}

\section{Keywords}

Grid-Based Fishery, Cellular Automata, Spatial Model, Fishery Management

\section{Introduction}

This paper traced back to a research project in constructing a multipurpose fi- 
shery management system. The author discarded the traditional approaches of fish population dynamics (e.g. the dynamic pooled model and the sigmoid curve theory model). The above models utilized maximum sustainable yield (MSY) as solution for fishery management. We look for solutions of other practical targets, namely, the Total Allowable Catch (TAC), or the Maximum Economic Yield (MEY). Our major concern is the interactive performances between the fishermen and the managers. We concentrated our work on fishing ground instead of biomass of fish population. For the last two decades, remote sensing and computing techniques have been widely used in fields of agricultural sciences. It is a high time to make new changes on fishery management. The so-called adaptive fishery management [1] seems more practical and suitable for the real situation. With the help of an arithmetic tool named cellular automata (CA) it is possible to simulate the behavior of fish population under various environmental effects. This study took advantage of the programming power of the Microsoft Visual Basic language (Microsoft Inc.), and merge with EXCEL spreadsheet. This resulted in a simulation and demonstration platform for the job. The detailed construction procedure and operation are given below.

\section{Methods}

1) Preparing the working platform

Our work begins by preparing an Excel spreadsheet as a working platform. Each cell represents a single grid of the fishing environment. The spreadsheet is created by dividing the fishing ground into unitary grid of equal area, each with predefined values of longitudes and latitudes (both in 0.033 degree or approximately $2 \times 2$ nautical miles in this study). Other sizes of grid can also be chosen, depending on the scale of the target area. On a high-resolution navigation map of Taiwan Island, draw horizontal and vertical straight lines, each match exactly the pre-decided values of longitudes and latitudes. This gives a grid-map paper sheet representing the target area. On the Microsoft EXCEL screen, create a spreadsheet representing the electronic image of the map above.

Referring to the navigation map above, carefully mark with mouse such that each individual cell fills up with one of the three colors, representing sea water surface, dry land or (mixed water and land) coastal area respectively (Figure 1). The working platform serves both for data storage and CA operations.

2) Data entering

Daily records of fishing boat operation were to be collected and key in to each cell during the next step. On this study our first worksheet is the number of fishing days (as variable of fishing effort) (f). The data were from the actual daily-catching report of all fishing vessel. By regulation of the government and the insurance company, fishing vessels are required to report their daily position through special radio station [2]. There are short cuts in EXCEL to rearrange the one dimensional-data array onto the 2-dimentional worksheet maps, by taking advantage of the pivot table function in EXCEL. We do not explained the detailed 


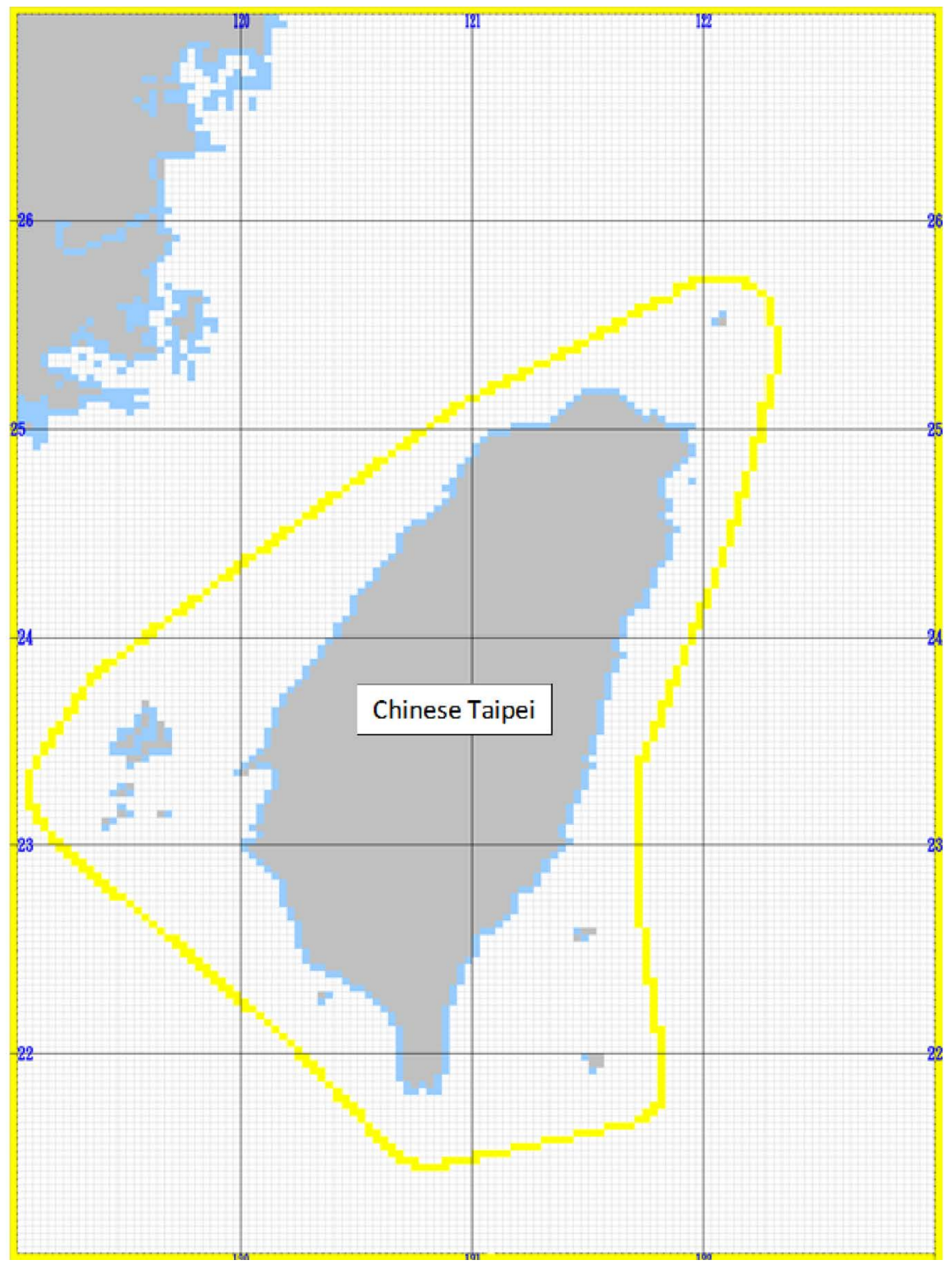

Figure 1. A working platform for data entering and CA simulation studies. Size of individual cell is 0.033 degree both in longitude and latitude (approximately $2 \times 2$ nautical miles). Dryland and coastal grids were marked as grey and blue in color respectively. Yellow line shows the official boundary line of exclusive economic zone (EEZ of Chinese Taipei) [6].

process here. Parallel worksheets for other types of data, such as fishing yield, water depth, benthic characters, speed of wind and water current, etc. can also be constructed respectively. This depends on the purpose of the research and if adequate data are available. All worksheets can be combined as one deck (workbook). Data from all cells can be linked by referring to the same (absolute) cell address across the deck, given rise to a practically-3-dimentional operating platform. The current workbook is served as a platform for direct analysis of spatial model for the near-shored mixed fishery. It is expected that other single and multispecies model can also be constructed in the same way if adequate data is available. 
Figure 1 shows the general lay out the position and relationship of the square-grids or spreadsheet cells. The figure is equal to an electronic two-way contingency table, showing the daily position records of the location of fishing vessels (mostly 5 to 100 Ton per vessel). Data were collected for the year between Jan. 1999 and May 2002. Since this study was a pioneered project, the author had only to deal with whatever data were available. Although the time scales from different sources were not exactly synchronized, they were each roughly within one calendar year of time and covering the major fishing seasons. In the future when annually continuous data can be collected, more standardized records should be used, or, certain kind of data weighting should be made if required.

3) Algorithm for data interpolation among cells

Each grid cell has four nearest neighboring cells (toward upper, lower, left and right directions) (the so-called Von Neuman neighboring system) as in Figure 2.

Value of each cell was first divided by the grand sum (here it is 22,823 boat-days) to transform into relative intensity values. During the CA process, value of each cell was averaged with the four neighbors, one step at a time until all cells were thoroughly processed. The averaging process repeats iteratively until no empty cells were left inside the whole area. There were various techniques named to the process of local interpolation, such as: moving averages, spline and kriging [5]. In this study the author named our method as the iterative $\{2-\mathrm{D}\}$ moving averages (IMA).

CA operation was done by programing with Visual Basic (Microsoft Inc.) langrage in the EXCEL system. While running the BASIC program, condition in each cell (grid) can be observed on the spreadsheet continuously.

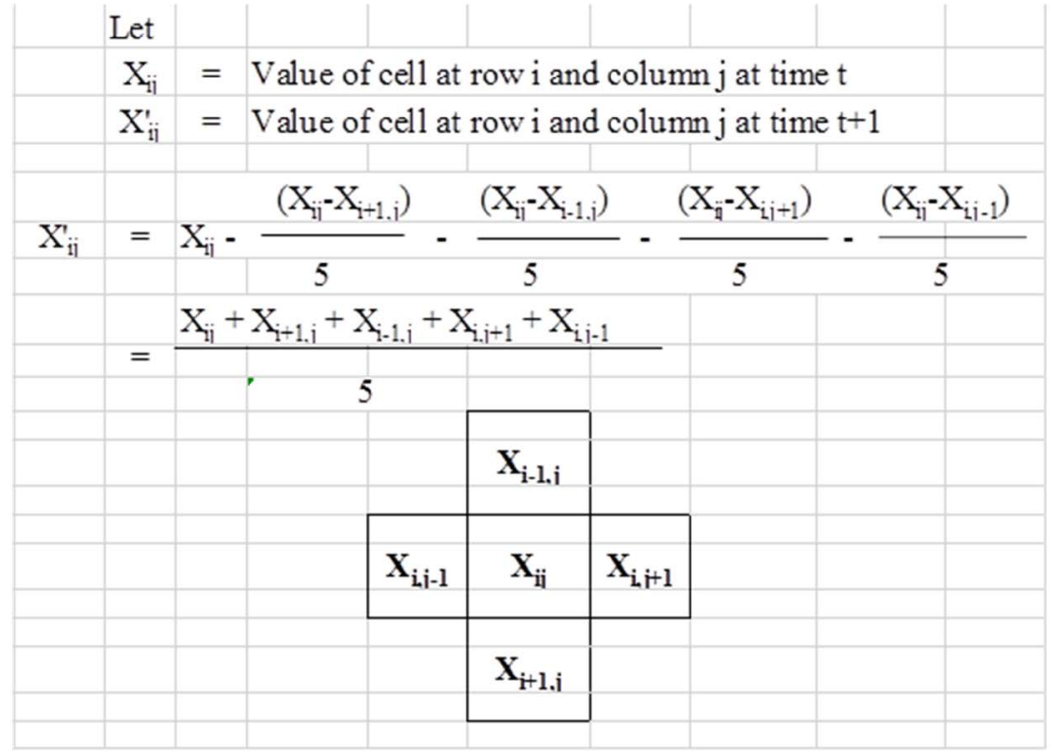

Figure 2. [Upper part] Formula for moving average estimation of individual cell. [Lower part] positions of the von Neuman neighboring cells during each step of CA operation. Note that values in the diagonal directions will be processed on the next step. Care has been taken to assure that the sequence of recalculation (e.g. column-wise or row-wise) does not interfere with the result. 


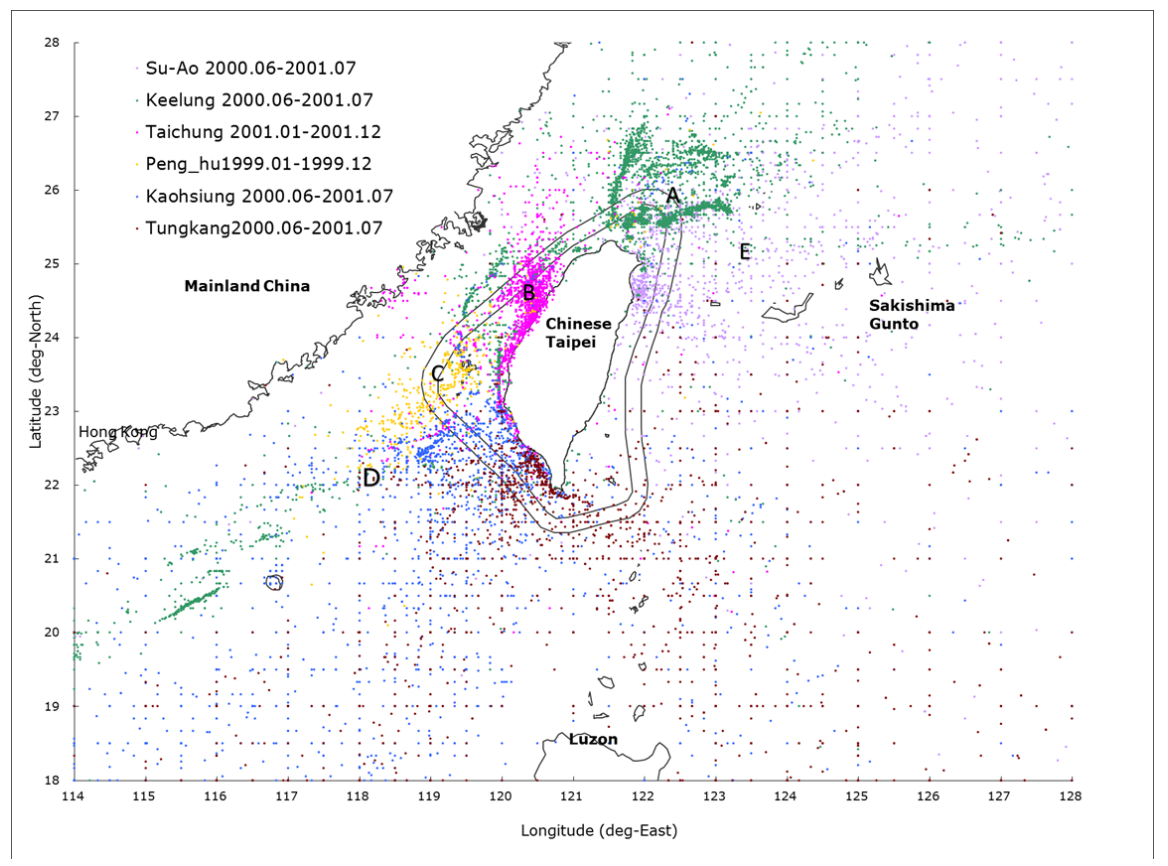

Figure 3. A scattering diagram showing the annual distribution of fishing boat from recordings of 6 radio stations in Chinese Taipei. Data were collected between 1999 and 2001. Different colors indicate different major types of fisheries. A: Mackerel Purse seiner; B: West coast near-shore; C: Migratory sardine fishery of Penghu; D: South-western trawling; E: Long liner for migratory species in the Kuroshio Current tributary. Solid lines stand for the 12 and 24 nautical mile boundaries of the official EEZ zone respectively [6].

\section{Results}

1) Distribution of different types fishing operation.

Although no thorough scientific survey on the fishing ground distribution around Taiwan has been done, spatial distribution of capturing fishery has been well-known. And it is clearly matched with Figure 3, whereas different colors indicate different groups of fisheries, which include: [A] The mackerel purse-seine fishery near the northern part of Taiwan; [B] The coastal fishery along the north-western coast; [C] The coastal fishery for the sardine-type fishery near Penghu Island; [D] The Trawl fishery on the south-western continental shelf area; $[\mathrm{E}]$ The wildly spread long liner fishery targeted to the migratory species in the Kuroshio current tributary on the east.

Preparing a 2-dimentional map like this required close and well-organized communication between individual fishing boats and the radio stations. These can be improved by real-timed governmental remote sensing facilities.

Managing such a fishery system depends on the so-called right-based fishery and the individual transferable quota (ITQ) allocation system. It is the authors suggestion that an interactive relationship between managing agent and local fishermen should be developed, such that fishing licenses be issued under the condition of reporting previous fishing records from the latter. Developments of such relationship are beyond the scope of this paper and can be referred to [3]. In the following section we will restrict our theory analysis on fishery management. 
2) Exploitation of fish population dynamic based on the spreadsheet platform

We begin the theoretical analysis by neglecting the traditional assumption of maximum sustainable yield (MSY) and go directly to the short-term target of total allowable catch (TAC) of the local fishing grids. The first step is to prepare the primary data sheet for one single calendar year in Figure 3. In the fallowing analysis, please note that we are dealing with individual cell instead of the whole fish population of one specific single species. However, some parameters (such as natural mortality or growth parameters of specific species) are assumed equal for the whole population in all grids.

In fish population biology, we have:

$$
Z=M+F
$$

Whereas $Z, M \& F$ stand for instantaneous total-, natural- and fishing-mortality coefficients respectively, and for value of $F$ is

$$
F=q \times f
$$

Which is the product of (unknown) catchability coefficient $(q)$, and fishing effort $(f)$ in Figure 3.

From traditional analysis such as Chapter 4 of [4], there have been methods to solve for the value of $Z$ and $M$ through growth curve studies. Linear regression analysis of $\mathrm{y}$-axis $=Z$ against $\mathrm{x}$-axis $=f$ provides estimation of slope $=q$. Value of $\mathrm{q}$ is assumed a constant over all cells for the same type of fishing method.

Thus, we have $F$ equals to $q$ times $f(F=q \cdot f)$ for each individual cell in Figure 3. Also In [4] Pauly estimate the stock size of reef fishes by

$$
Y=F \cdot B
$$

where $Y$ stand for fishing yield in weight (from the catch record) and $B$ is the unknown biomass in each cell. Thus,

$$
B=Y / F
$$

The total biomass of the entire fish population during that special year is the grand sum of $B$ over all cells.

It is expected that with annual catch record provided, a series of total biomass will be achieved. This gives rise to the theoretical base for the estimation of total allowable catch (TAC) for the manager. Estimation of maximum economic yield (MEY) can be achieved with marketing value of the fish available. During the above approach, assumptions on a balanced population, or maximum sustainable yield (MSY) will no longer be required. And fishery management moves toward more realistic considerations.

3) Transformation and integration of fishing effort data

In geographic information system (GIS) analysis, spatial interpolation is done mostly by calibration along a straight line between specific two points nearby. This method is not adequate here when, considering the cell values (number of days of fishing annually) fluctuate between fishing and are different from on solid landscape. Here we use CA operation to interpolate neighboring values of every cell. By taking moving average continuously for indefinite steps of time 

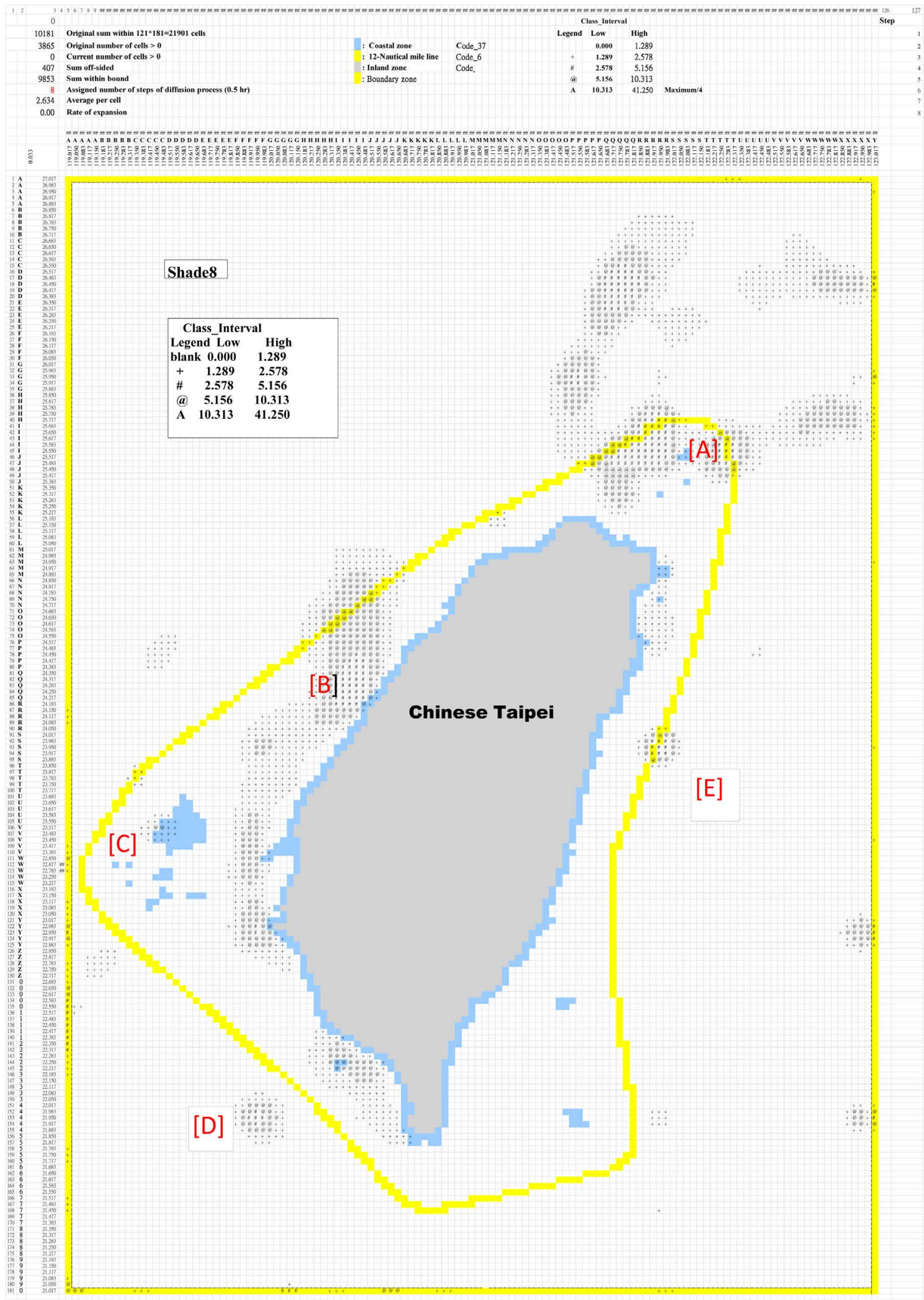

Figure 4. Results of iterative 2-Dmoving averages (IMA) of grid values to show a general picture of fishing intensity distribution. There are no empty grids in between as they were all filled up during the CA processing. Yellow grids mark the 12 nautical mile line of the EEZ boundary. [A], [B], [C], [D] and [E] stand for different types of fishery as described in Figure 3. 


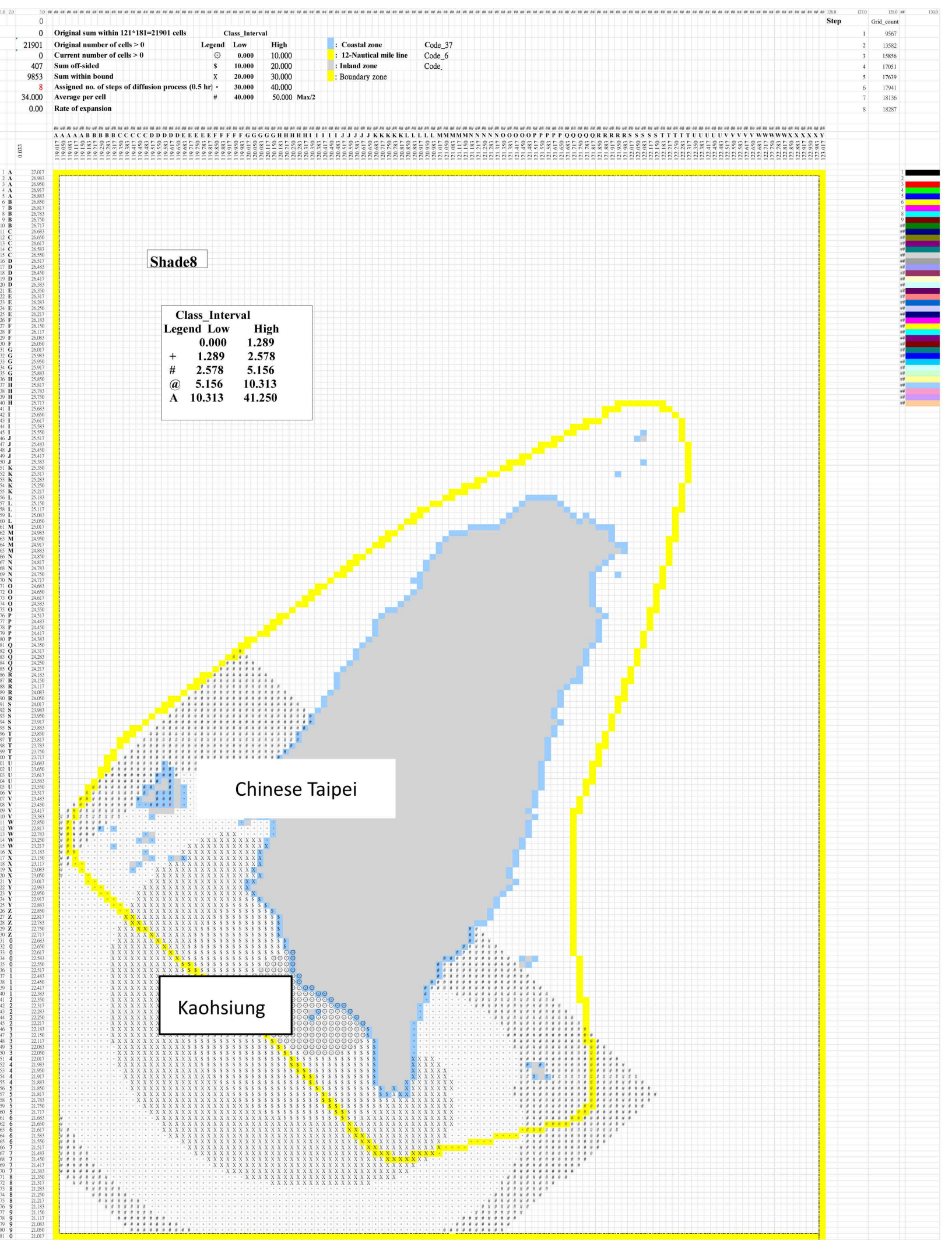

Figure 5. Part of the results of CA simulation to estimate the distances originated from Kaohsiung harbor. Grids of same distance group mark with identical shad. Each grid is 4 by 4 nautical miles. The exact value of distance can be estimated in another sheet [6]. 
until most values (say, 95\% or more) of all cells were occupied [5]. This operation is done by programing with Visual Basic.

Figure 4 is the first time a picture of the near-shored fishery activity in this area is drawn through computer data processing. The result of the named IMA method appeared to be satisfactorily. Such a standardized worksheet will be used to deck up with other parallel-ecological-datasheet (benthic environment, water temperature, current, etc.) for analysis in fishery ecology [6]. Purpose of this transform is to create a consistent picture which gives a generally robust and "fuzzy" appearance of value distribution. It is taken as a worksheet representing the year of 2000 and decked up with other synchronized ecological datasheet such as water temperature on the same year for further analysis.

4) Theoretical distances between fishing harbors.

Figure 5 showed that from any specific fishing port, distances from one to any other ports or to the relative fishing grounds can be estimated [7]. It can be combined with information of boat speed and fuel requirement for better operation of navigation control. These make the job of assigning fishing rights more logically and systematically for the government. Also, it helps the fishermen's society to provide services and man power for the benefit of the fishermen.

\section{Innovations and discussions}

We changed the formula of interpolation on Table 2 by adding an extra weighting factor $(p)$ for each neighboring cell as follows:

$$
X_{i j}^{\prime}=X_{i j}+\frac{p_{1}\left[X_{i+1, j}\right]+p_{2}\left[X_{i-1, j}\right]+p_{3}\left[X_{i, j+1}\right]+p_{4}\left[X_{i, j-1}\right]}{5}
$$

Whereas $\mathrm{p}_{1}, \mathrm{p}_{2}, \mathrm{p}_{3}$ and $\mathrm{p}_{4}$ are the weighting factor for each cell respectively. It is a more general form than the formula in Figure 2 where $p_{1}=p_{2}=p_{3}=p_{4}=1$. The values of the p's were to be assigned manually and the resulted value of (X') would be different. The sum of all p's can be equal to one. One example is the simulation of mullet migration to the direction of south-west along north-western coast of Taiwan, the use of empirical p-values has shown preliminary successful results. If the sum of all p's is less than one, grid values become less and less. A CA model was constructed for demonstrating oil pollution impact (for educational purpose [8]). During that simulation of oil-leaking trace prediction, some oil slag was assumed to be trapped onto the surface of the beach.

This spreadsheet model also seems suitable for the design of marine protected area (MPA) zonation and monitoring system. These new developments yet to be exploited.

The technique of CA and application has been well-developed and documented as in [9]. However, to the best of the authors knowledge, it had not be well adopted and used in fishery science. For unknown reasons the theory and methodology in our field has been changing rather slowly for the past 30 years. This paper was a newly venture before my retirement. Hopefully, the concepts here may still be worthwhile in the field of fishery management. 


\section{Acknowledgements}

Large part of the results in this report was funded by the Council of Agriculture (COA), Chinese Taipei, between 2002 to 2004. Thanks to Shu Chia-chin, who was my graduate student in the Institute of Marine Biology, National Sun Yat-sen University, for computer data processing to create the spreadsheet maps.

\section{Conflicts of Interest}

The author declares no conflicts of interest regarding the publication of this paper.

\section{References}

[1] King, M. (1995) Fisheries Biology, Assessment and Management. Fishing News Books, $341 \mathrm{p}$.

[2] Taiwan Fisheries Research Institute (2002) Daily Reports of the Radio Stations for Positions of Fishing Vessels of Taiwan. http://www.tfrin.gov.tw/scripts/

[3] Morgan, G.R. (1997) Individual Quota Management in Fisheries: Methodologies for Determining Catch Quotas and Initial Allocation. FAO Fisheries Technical Paper No. 371, 41 p.

[4] Pauly, D. (1984) Some Simple Methods for the Assessment of Tropical Fish Stocks. FAO Fish. Tech. Pap., 234, 52 p.

[5] Johnson, C.A. (1998) Geographic Information System in Ecology. Blackwell Science, London, $239 \mathrm{p}$.

[6] Fong, S.C. (2002-2004) Project Reports on the Estimation of Total Allowable Catch (TAC) and Grid-Model Construction for the Near-Shored Fishery Management of Taiwan. The Council of Agriculture (COA). (In Chinese).

[7] Fong, S.C. (2004) Using Cellular Automata to Estimate the Grid-Distances between Different Fishing Harbors along the Coast of Taiwan. Conference of Taiwan Fisheries Society, Taipei, 25-26 December 2004.

[8] Fong, S.C. (2001) OILYSPREAD: A Spreadsheet Model of Oil Drift along the Coast of Southwestern Taiwan, Using Cellular Automata. 6th Asian Fish. Forum, Asian Fish. Soc., Kaohsiung, 25-30 November 2001.

[9] Li, S., Yeh, C.A., Liu, S.P. and Young, C.S. (2006) Simulation of Geographical System: Cellular Automata and Multi-Agents. China Science Publishing \& Media Ltd., 312 p. (In Chinese) http://www.sciencep.com/ 